\title{
Eskola eta irratia: EHko 5 haur-irrati, Arabako 6 eskola-irrati eta Gasteizko Alai Bediren esperientzia
}

\author{
Mikel Gartzia Santamaria \\ Lehen Hezkuntzan Graduatua \\ Hezkuntza eta Kirol Fakultatea \\ Euskal Herriko Unibertsitatea (UPV/EHU) \\ Jon Bustillo Bayón \\ Didaktika eta Eskola Antolakuntza Saila \\ Hezkuntza eta Kirol Fakultatea \\ Euskal Herriko Unibertsitatea (UPV/EHU)
}

DOI: $10.1387 /$ tantak.16338

GAKO-HITZAK: Herritartasunerako hezkuntza, Lehen Hezkuntza, Irratia, Eskola-irratia, Arrail digitala, IKT.

\section{SARRERA}

Umeak informazio iturri oso indartsuekin bizi dira gaur egun. Eskolak zeukan hezkuntza ahalmenaren zati handia galdu du eta neska-mutilak prestatu egin behar ditu iristen zaien informazioa kritikoki kontsumitu ahal izateko. Aspaldi hasi zen UNESCO (1982) iragartzen hedabideak nonahi zeudenez hezkuntzak errealitate hori ez zukeela ukatu behar, eta egoera hori areagotu eta azkartu egin da geroztik. Alfabetatzea mekanikoki irakurtzen eta idazten irakastea baino gehiago da eta herritarrak, informazio kontsumitzaile manipulagarri ez izateko, jakin egin behar du nola sortzen diren mezuak. Hori ulertzeko igorlearen lekuan jartzea oso baliagarri dela premisa gisa hartu zen lan honetan, eskolak ezinbestean egin behar ditu halako ekimenak (eskolako aldizkaria, irratia...).

Hezkuntzan irratia erabiltzeari buruz aurkituriko dokumentazio gehiena nahiko zaharra da (Millares et al., 2003) eta irratia, ikus-entzunezkoen artean, bazterreko gisa agertu ohi da. Irratia egiteko tresneria aspalditik merkea den arren, hezkuntzan irratiaren erabilera bigarren mailakoa izan dela diote Mallasek (1979) eta Porcherrek (1980). 
Berezia da irratia. Mallasen ustetan irudiaren eta soinuaren tratamenduak oso ezberdinak dira: «Irudia gelditu eta aztertu egin daiteke, baina soinua bere segida horretan hauteman behar da; ezin da melodia puska bat, akorde bat, ez eta fonema linguistiko bat ere finko eduki, aditzeko.» (Mallas, 1979, 197. or.). Soinuaren pertzepzioa prozesua denez, mezu filmikoarena bezala, gidoia egitea ezinbestekoa dela dio Mallasek. Tresna (gure kasuan irratia) bigarren mailan jarri behar dute gidoiak edo helburu didaktikoek. Bere hitzetan:

«Ikus-entzunezko laguntzak, baliabide horren laguntzarik gabe erabilgarri izango litzatekeen gidoi didaktikoa jarraituz aplikatu behar dira (...) horrela bermatzen delako tresna ikaskuntzaren zerbitzura jartzea, makinen fetitxismoa saihestea eta didaktikarekin loturiko helburu kontzeptuaren indarra tazituki onartzea» (Mallas, 1979, 239. or.).

Askotxo esatea izan liteke, baina egia da irratian gidoia prestatzea ezinbestekoa dela. Lan hau egiteko garaiz ezagutu ez zen arren, bada UEUk argitaratutako lan bat irratsaio-gidoien idazketan trebatzeko erreferentziazkoa dena (Gutierrez eta Fernandez, 2005). Eta ondoren gidoia ondo irakurri behar da, noski, Joxe Juan Ugaldek bere liburuxka oso gomendagarrian dioen bezala (Ugalde, 2008).

Hala ere, zuzenekoak ez diren audio-lanentzat Mallasek (1979) jadanik adierazten zuen soinu-espektroa pantailan «ikusteko» aukera zein aurrerapauso lagungarria den, eta halaxe dela berretsi zen lan honetan (Audacity editorea erabili zen).

Irratia kontuan hartu beharreko baliabidea da: berarekin erraz, ia ezinbestean, hizkuntza gaitasuna lantzen da (ahoskera, intonazioa, testuen prestaketa, lankidetza harremanak, entzumena...). Porcherrek (1980), adibidez, bi ildo aipatzen ditu: motibazioa (ikasleari mintzoa askatzea) eta behaketa (ondoren, joskera hobetzeko, zein ariketa prestatu planifikatzeko). Esatariak produktua entzun eta hausnarketa egitea ere garrantzitsua da, ordea, ikaskuntza gerta dadin (Aparici et al., 1993). Izan ere, «hizkuntzaren alderdi linguistiko, soziolinguistiko eta pragmatikoei buruzko hausnarketa» egitea beharrezkoa da (Eusko Jaurlaritza, 2009) eta horretarako testuinguru bikaina da irratia. Gidoia kontrolatuz, ama-hizkuntza (H1) edo H2 lantzeko, Ruiz Bikandik proposatzen duen bezala «ikastaldearentzat hitza gero eta modu askotarikoagoan erabiltzea» eragin dezake irakasleak, «solaskide eta jendaurreko egoerek formei arreta berezia jartzera behartu ditzaten haurrak.» (Ruiz, 2009, 206. or.).

Halaber, curriculum ofizialetan bertan aipatzen da irratia erabiltzeko aukera. EAEko dekretuan (2007):

[HIRUGARREN ZIKLOA. EDUKIAK. 1. eduki multzoa. Ahozko komunikazioa: entzutea, hitz egitea eta elkarrizketan aritzea] «Parte har- 
tzea eta laguntzea gizarte-harremanezkoak eta ikasizkoak diren komunikazio-egoera hauetan: Hiztunaren rol berriak: taldearen ordezkaria izanda, aditu gisa...; Solaskide mota berriak: ezezagunak (beste ikastetxe batzuetako ikasleak), edo zehaztugabeak (irratientzuleak etaledo teleikusleak); Harreman zuzenetan nahiz eskolako grabazioen etaledo komunikabideen bidez eginak; Xedea: adieraztea, informatzea, konbentzitzea ...» (Eusko Jaurlaritza, 2007, 29.or.).

Esplizituago Nafarroa Garaikoan (2014):

«12.4. Parte hartzen du elkarrizketa batean, elkarrizketatzaile edo elkarrizketatu gisa (adibidez, norbaiti elkarrizketa eginez eskolako aldizkarirako, edo irrati edo telebistako saio simulatu batean, etab.)» (Nafarroako Foru Aldundia, 2014, 84. or.). (2002):

Eta Ipar Euskal Herrirako dokumentu ofizialetan ere aipatua izan da

«La progressive maîtrise de la compréhension de ce langage passe par des activités mettant en jeu des situations d'échange avec les familles («livre de vie»), de correspondance interscolaire, en particulier par le moyen du courrier électronique (l'enseignant est dans ce cas le lecteur des messages reçus). Elles peuvent aussi s'appuyer sur l'échange de cassettes, l'usage de la radio ou de la vidéo... Les discussions sur la signification des énoncés entendus permettent des interaction identiques à celles qui ont lieu lors d'activités de production.» (Frantziako Gobernua, 2002, 20. or.).

Gainera, lantzen diren oinarrizko gaitasunen artean hizkuntzarena nagusi izan arren, irratikoa komunikazio ekintza izanik, beste edozein arlo ere landu daiteke berarekin. Aitzitik, autore ugarik aipatzen dute Espainiako hezkuntzan irratia gutxi eta emaitza eskasekin erabili izan dela (Sevillano et al., 1998), irrati bidezko hedabideak 1923az geroztik erregulatuta dauden arren. Irratiarekin ikasteko bi ikuspegi daude: entzule gisa eta esatari gisa. Esatari gisa aritzean komunikabidearen gertutasuna eta izaera bera ulertzen dira eta bi aldeen ikuspegi orokorragoa lortzen da. Izan ere, irratsaioa entzungarri egiteko garrantzitsua da beste aldekoari hitz egiten ikastea (Ugalde, 2008).

Derrigorrezko hezkuntzan zehar neska-mutil oro esatariaren lekuan jarriz, gizartean arrail digitala saihesten laguntzen da. Kontzeptu hori Ambròs eta Breuk (2011) ulertzen duten moduan, gainera: «Komunikabideen Hezkuntza gai tekniko gisa bakarrik landu ordez, arlo teknikoaz gain teknologien helburuen inguruko hausnarketa, eduki etikoak, analisiaren ingurukoak eta kritikoak» ere jasoz. Arrail mediatikoa deitu ahal zaionak 
bereizi egiten ditu komunikazioa menperatzen duten pertsonak (gure emozio, nahi, amets eta ideiak diseinatzeko gai direnak) eta soilik komunikabideen kontsumitzaile direnak.

«XVIII, XIX eta ia XX. mende osoan zehar teknologiaren garapena gizateriaren mesedetan zetorrela sinetsi da, baina gaur egun herritar askok ez dute garapen horren helburua garbi ikusten eta zenbait garapen zientifiko-tekniko mota, gizateriaren zerbitzurako baino, haren esplotazioaren zerbitzurako datorrela ere sumatzen da.» (Ambròs eta Breu, 2011, 28. or.).

Alienatze hori sahiesteko, garrantzitsua da komunikabideetan parte hartzea. Jasotzen dugun irudi (mezu, ideia) zaparrada noranzko bakarrekoa dela eta komunikabide handi horiek, teknikoki erraza izanik, bi noranzkoetan gehiago garatu ez izana susmagarria dela aipatzen dute Ambròs eta Breuk (2011). Illichek ere aipatzen zuen, egoera zapaltzailea adieraziz, komunikabide aparailuak jasotzeko bakarrik direla, inori ez zaiola bururatzen irratiak esandakoari erantzuten hastea zerbait gaizki esaten duenean, erotuta bageunde bezala begiratuko bailigukete (Illich, 1971). Informazioaren kontsumitzaile soil izanda ez dago eztabaidarik eta, ondorioz, ez dago inteligentzia propiorik, ez askatasunik. Irtenbidea erraza da: «Don't hate the media, become the media». Esaldi hori Jello Biafra punk abeslari eta aktibista estatubatuarrarena da. Internetaren eta sare sozialen hedapenarekin batera egin zen entzutetsu esaldia eta aldarri anarkista gisa har daiteke, behetik gorako politika egiteko, norberak ardura hartzeko dei gisa. Irratia egitea, nolabait irrati izatea, kontsigna horren adibide praktikoa da.

Irrati bidezko hezkuntza, izan ere, bi modutan uler daiteke: batez ere entzuleek ikasteko egiten dena edo esatariek ikas dezatela lortu nahi duena. Historikoki lehenengoa izan da nagusi. Herrialde atzeratuetan helduen hezkuntzarako bideratu izan da irratia, modu liluragarri bezain eraginkor eta, baita ere, goitik beherakoan (UNESCO, 1950). Ambrós eta Breuren (2011) lanean, berriz, eta geure ikuspegitik ere bai, entzulearen ikaskuntza beharrean esatari lanean jartzen den pertsonarena da baliotsua, batez ere. Autore horien ustez »...kritikoki irakurtzeko lana errazago bihurtzen da mezuen produkzioan aritu ondoren». Horretarako, ordea, benetako irakurleria edo entzuleria behar da eta...

«hasieran, ikasleei proposatzean, ezezko borobila jasotzea ohikoa da, inork bere lana ikusi edo entzuteak lotsa ematen diela esanez, baina barru-barruan bere lanaz harro eta ondo egiteko arduratsu sentituko direla pentsatu behar du irakasleak». (Ambròs eta Breu, 2011, 119. or.) 


\section{HELBURUAK}

Lan honen helburua irratia erabiliz eskolek edo irrati profesionalek egiten zuten lan hezitzailea ezagutzea izan zen, 2014-2015 ikasturtean. Aldi berean, Gasteizen (Hala Bedi Irratian) eskolaz kanpoko orduetan haur-irratsaio berria sortu nahi zen eta Lehen Hezkuntzako irakasleei irratsaio horretan parte hartzea eskaini nahi zitzaien.

\section{MATERIALAK ETA METODOAK}

\section{Irrati esperientzia didaktikoen bilaketa nola egin zen}

Informazio bilaketarako metodoa ez zegoen sistematizatuta ikerketa hasterakoan. Posta elektronikoa, Google-en bilaketak, Twitterren galdetzea, eskoletara bertaratzea, WhatsApp, Telegram eta Skype izan dira bide erabilienak, hurrenez hurren.

Lana egiteko Arabako eskola batzuetara bisitak egin ziren, irratiarekin harremana duten esperientzia batzuk kualitatiboki bilduz. Ondoen ezaguturikoa Kanpezukoa izan zen, behaketa parte-hartzailea (Woods, 1987) egin ahal izan baitzen, bertan egindako egonaldiari esker (Graduko Practicum III, azaroaren 4tik urtarrilaren 23ra).

Aurrerago, Twitterren galdetuz, esperientzia askoren berri izan zen eta, ondoren, posta elektroniko bidez, Bizkaia Irratiarekin, Iparraldeko Euskal Irratiekin, Xorroxin Irratiarekin, Ttan Ttakun Irratiarekin... harremanetan jarriz jaso zen haien esperientzien informazio zehatza. Odon de Apraiz Ikastolakoekin eta Antxeta Irratikoekin, berriz, Skype bidez egin ziren bideo-deiak.

\section{Irratsaio bat egiteko baliabideak eta partaideak}

Tresnei dagokienez, Hala Bedi Irratiko baliabideak (ordenagailuak, mikrofonoak, entzungailuak, estudio intsonorizatuak...), smartphone bat (WhatsApp aplikazioa eta soinu grabagailua), ordenagailu eramangarria, audioen ediziorako Audacity software askea eta WeTransfer plataforma (gurasoei irratsaioak helarazteko) izan ziren garrantzitsuenak.

Haurrak erakartzeko, berriz, irratiaren ondoko mendi-elkarte batera jo zen lehenik eta, aurrerago, Adurtza eta Salburua ikastoletan eskolaz kanpoko ekintza gisa irrati-tailerren aukera eskaini zen ohar baten bidez. Gurasoekin WhatsApp aplikazioaren bidez koordinatu eta gutxi gorabehera 15 egunero eraman zituzten haurrak irratira. Haurrak iristean, estudio barrura sartu aurretik 15-30 minutuz hitz egiten genien (saiorako zerbait ekarri zuten galdetu, irakurriko zuten ipuina prestatu, ordenagailuak piztu...); 
estudiora sartu eta 40-50 minutuz aritzen ginen grabatzen; ondoren, grabaturikoa editatzen zen, 30 minutuko irratsaioa borobilduz; eta, azkenik, igortzeko prest irratiko programazioan txertatzen zen eta gurasoei ere bidaltzen zitzaien .mp3 fitxategia, WeTransfer bidez. Saioak egiteko gutxienez bi haurrek etorri ahal izatea bilatzen zen, eta beti bikote berak ez elkartzen saiatzen ginen.

Irratsaioan erabiltzeko edukitzat Arabako gida. Haurrek egina (Arnal et al., 1998) eta sarean aurkituriko beste material batzuk baliatu ziren. Adibidez: aittu.net-eko ipuin irakurriak (Eizagirre, 2015), haurrek irakurtzeko mikroipuinak (Euskara Kultur Elkargoa, 2010), esaera zaharrak (Areizaga, 2012), asmakizunak, txisteak, marrazkiak, abestiak, albisteak, errezetak, eguraldia... Haurren bizipenak eta momentuko gaiak ere izan ziren hizpide (Gabonak, Korrika...).

\section{EMAITZAK}

Lehenik eta behin, teorikoki eta modu lausoan, Simulazio metodoa ezagutu dugula aipatu behar dugu. Ikasgelan bertan, izara baten atzean ezkutatuta, ikaskide batzuek besteentzat balizko irrati emanaldi bat egitean datza:

«...oihal handi bat erabili genuen. Honen atzean irratsaioa muntatu genuen eta geratzen zen zatian zehar ikasleei nahi zuten moduan zeudela entzutea soilik eskatu zitzaien.» (Ortego, 2014, 20. or.)

Metodo hau ez zen praktikan ikusi, baina egindako ikerketa honetan aurkikuntza interesgarria izan da. Lehen Hezkuntzako irakasleak irratia nola egin probatu nahi badu, lehen saiakera gisa oso erakargarria da antzerkitxo hori.

Emaitza nagusi gisa, beraz, hiru multzo ditugu: eskolekin harremana duten edo haur-irratsaio propioa egiten ari diren Euskal Herriko 5 irrati ezagutu ziren; Araban 6 eskolak irrati baliabidearekin duten harremana aztertu zen; eta, azkenik, 2014-2015 ikasturtean, Gasteizko Hala Bedi Irratian, Alai Bedi haur-irratsaioa sortu zen.

\section{EHko haur-irratsaioak}

Nafarroa Garaian Baztan aldeko Xorroxin Irratikoak duela 20 bat urte hasi ziren irrati-tresneria ibiltaria eskolei eskaintzen (Ambròs eta Breu, 2011). Behin aparailua eskolan paratuta ikasle-irakasleei gutxieneko irakaspenak ematen dizkiete. Ondoren, eskolako eragileen esku gelditzen da irratsaioa prestatu eta igortzea. Aparailua gehienez ere astebetez egoten 
da eskola bakoitzean eta herri horretako eremuan hedatzen da irratsaioaren emankizuna.

Ipar Euskal Herrian, berriz, Euskal Irratiak federazioa dago (lau irratik osatua: Gure Irratia, Antxeta Irratia, Xiberoko Botza eta Irulegiko Irratia). Antxeta Irratiko Aitziberrek azaldu zigun eskolaz kanpokoa euskaraz egin ahal izateko Irrati Tailerrak eskaintzen dituztela: haurrek ezer ez jakitetik programa bat nola egituratu, elkarrizketak nola egin... jakin arte. Orain dela 10 urte hasi ziren eta gidoia beti izaten dute prest irratikoek, baina oso aldakorra omen da taldearen arabera. 6-10 urte arteko neska-mutilekin egiten dituzte irratsaioak. Grabatuak izan ohi dira eta Audacityrekin editatzen dituzte. 5-10 minutuko saioak izaten dira emaitza. Frantziar estatuko eskolak zikloka aritzen dira: 7 astez klaseak daude eta 2 aste jai izaten dira. Antxeta Irratian, adibidez, ziklo bakoitzean 5 eskolari eskaintzen diete tailerra, astelehen-ostiral eskola bakoitzari egun bat egokituz; zazpi saioko tailerrak, beraz. Gehienetan irratia (mikrofonoa, ordenagailua, grabagailua, kaskoak eta, tarteka, mahai mugikorra) eskolara eramaten da eta aukera dagoenean haurrak irratira joaten dira. Irulegi Irratian ere Ondaiziela irratsaioaren baitan haurrekin tarte bat egiten da.

Gipuzkoan, Donostiako Egia auzoko Aitor Ikastolak Ttan Ttakun Irratia erabiltzen du (goo.gl/leCcPD). 1996 inguruan hasi ziren eta eskolan grabatzen dute, LHkoek. Talde bakoitzak urtean saio bat egiten du eta prozesuan zehar eskolako irakasleek autonomia handiz erabiltzen dute irratia: bi irakasle arduratzen dira irratsaioaz, irratsaioa beraiek igotzen dute irratiaren zerbitzarira, irratiko kideei lanik eman gabe, eta sistema informatikoak berriz eman egiten du 30 minutu beranduago.

Hondarribiko Talaia eskolan ere 15 urtetik gora daramate irratia egiten (goo.gl/rkTZY1) eta Bergarako San Martin Agirre herri eskolan ere irratia egiten dute, zuzenean.

Bizkaian, berriz, Bizkaia Irratiko haur-irratsaioak «Dona-Dona» izena dauka eta egiten duten bitartean online ere entzun daiteke zuzenekoa, 8:00etako albisteen ostean. Gero, ordea, saioak ez dira online jartzen. Irratiak 25 urte bete ditu 2015ean eta beti izan da umeentzat saioren bat, beti lehiaketa formatoan. 12 urtera arteko gaztetxoek parte hartzen dute, telefonoz. Gaur egun gaztetxoenek 5 urte dituzte eta $20-25$ bat ume dira, guztira, parte hartzen dutenak. Urtean birritan opariak banatzen dizkiete, Gabonetako banaketarako irratira gonbidatzen dituzte eta orduerdiko saiotxoa egiten dute eurekin.

Eskolek ez dute parte hartzen. 2010 inguruan Bizkaiko eskolei eskaini zieten irrati-tailertxo bat egiteko aukera, hiru parte zituena: eskolan bertan ikastarotxo laburra, saio labur bat grabatzea eta irratira bisita. Urte batean egin zuten, lauzpabost eskolarekin. 
Bestalde, Dona-Dona irratsaioaz gain, Bertsozale Elkartearekin eta Bilboko Udalagaz «Zortziko Txikia» saioa ere egiten dute, orain dela 15 urtetik hona. Urtean zehar eskolan lantzen dute bertsolaritza eta astean behin ikastetxe batera joaten dira Bizkaia Irratikoak, bertsoak nagusi dituen irratsaioa grabatzera. Zapatuetan, goizeko 11:30ean igortzen dute eta bizkaiairratia. eus webgunean «Audioteka» atalean jasota daude saioak: goo.gl/3jGsqH.

Eta Bizkaian, azkenik, Bilbo Hiria Irratian ere haurrentzako irratsaioa egiten dute, kasu honetan esatari helduek: «Gaur Ez Dago Eskolarik» (goo. $\mathrm{gl} / \mathrm{LTJ} 3 \mathrm{Fh})$.

Araban, ordea, Radio Vitorian euskara erabiltzen hasi ziren garaian Maritxu Berritsu irratsaioa egiten zen eta Hala Bedi irratian Txorro Morro saioa ere bazegoen, baina biak bukatu egin ziren eta lurralde honetan ez genuen haur-irratsaiorik ezagutzen.

\section{Arabako eskola-irratiak}

Gasteizko Ramón Bajo Ikastetxea eta Salburua Ikastola. Txanela liburuetako batean («Gora Gutenberg! Gora Marconi!», Ikastolen Elkartea, 2003) proposatzen den proiektu bat dela eta, Hala Bedi irratira eramaten dituzte LH 2. mailako ikasleak (Ramon Bajokoek 2005 eta Salburuakoek 2012 ingurutik). Lehenengo, apirilean edo, irratiko estudioei bisita egiten diete, nolakoak diren ikusteko (ordenagailuak, mikrofonoak, entzuteko kaskoak, moketadun hormak, fonotekako CD piloa...); ondoren, hilabete inguruko tartean, gidoia prestatu eta entseatu egiten dute eskolan; eta, azkenik, Hala Bedira itzultzen dira irratsaioa grabatzera. Lauko taldetan sartzen dira estudioan, gainerakoek kalean jolasak egiten dituzten bitartean. Talde horietako batek grabatzen ditu hasierako aurkezpena, tarteen izenak, entzuleei hitz egitea eta azken agurra; beste ikasleek, banaka edo bikoteka, irratsaioko atalak grabatzen dituzte (errezeta, txisteak, albistea...). Ondoren heldu batek editatzen du saioa.

Gasteizko Adurtza Ikastola. 15 urtetik gora daramate megafonia bidezko barne-irratia egiten, Zuzendariaren bulegotik. Ostiralero lauzpabost ikasleri tokatzen zaie: gidoi bat oinarri hartuta idatziz prestatzen dute saioa eta aurreko egunetan pare bat aldiz entseatu ondoren, ostiralean 9:00etan zuzenean irakurtzen dute. 9-12 urte artekoek egin ohi dute irratia eta megafonia bidez 3-12 urte artekoen ikasgeletan entzuten da.

Umandi Ikastola. Ikastola honetan ere irratiaren erabilerak historia luzea du, 2005-2006 ikasturtean hasi ziren. Hasieran zuzenekoak egitea pentsatu bazuten ere, segituan ohartu ziren horren zailtasunaz eta grabazioak egin dituzte orain arte. LHko mailetarako irrati bat (Kontu Kontari) sendo hasi zen arren, orain (2014-2015) HHkoa bakarrik dago martxan (Bil bil bil Irratia). 
Haur Hezkuntzako tutoreak, beraz, haur bakoitzarekin grabazioak egiten ditu (imitazioz, errepikapenez) ordenagailuari konektaturiko mikrofono merke batekin (aparrezko pailazo sudurra jarrita, soinua hobetzeko eta erakargarri egiteko). Ondoren, Audacityrekin editatu (garbitu, elkartu eta musika jarri) eta CD batera pasatzen du saioa. Ostiraleko goizeko 9:00etan igortzen da ikasgeletara megafonia bidez eta, azkenik, saioak blogean ere jartzen dituzte: goo.gl/QrfDat.

Odon de Apraiz Ikastola. Gasteizko Odon de Apraiz ikastolan Txutxu-Mutxu irratia egiten dute. 2013-2014an hasi zuten Euskara Batzordeko hiru irakaslek, ahoskera lantzeko, eta 3 urteko ume baten aitak ere grabaketan eta irratsaioak zerbitzarian jartzen lagundu zuen.

Lehen urtean astero eta 2014-2015ean 15 egunero egin zuten irratsaioa. HH eta LHko adin guztietakoek egiten dituzte irratsaioak eta denek entzuten dute gero, ostiraleko lehen orduan. Kasu honetan ez da megafonia bidez igortzen. Irratia egiteko gela berezia prestatu zuten, bertan grabatzen da saioa eta Audacityrekin editatu ondoren ikastetxeko ordenagailuen zerbitzarian sartzen da. Ondoren, ostiral goizean, tutoreek gutxi gorabehera une berean arbel digitaletik erreproduzitzen dute ikasgela bakoitzean. Bestalde, irratsaioak gero blogean jartzen ditu zuzendariak: goo. $\mathrm{gl} / \mathrm{D} 4 \mathrm{aENM}$.

Tutoreek txantiloioa daukate saioa prestatzeko, baina askatasuna dute hura aberasteko. Eduki edo gaitasunak berariaz lantzeko ez dute planifikazio handirik, eta ebaluazio idatzirik ere ez dute egiten, ebakera eta haurren ahozko euskara jarioa askatzea da helburu nagusia. Egiten dituzten atalen artean aipagarriak dira A, B, C, D erantzun posibleen galdera-lehiaketak.

LH 6. mailako ikasleek audioa editatzen ikastea eta saioa zerbitzarira beraiek igotzea zuten aurrera begirako helburua, haurrei autonomia gehiago emateko.

Kanpezuko Mendialdea IPIn ere orain dela gutxi hasi ziren (20132014 ikasturtean), baina bikain ari dira. 15 egunean behin egiten dute irratia, ostegun arratsaldez. LHko taldeek (lerro bakarra dago) bina irratsaio egiten dituzte urtean eta irratsaio bakoitzean txertatzeko HHko ikasleek abesti txiki bat grabatzen dute gelan (5 urtekoek egin ohi dute; azken saioan 4 urtekoek).

Irratsaioek lehiaketa modukoa dute eta, sorgin-gurpila osatuz, saio bakoitza aurreko irabazleen izenak esanez hasten da: talde batek egiten du eta beste gela guztiak adi daude, amaieran ikasmaila bakoitzari galdera bat egiten baitzaio saioan zehar aipatu diren gauzen inguruan (dinosauroen inguruko zerbait, etxeko txirrinaren funtzionamenduari buruz...). Ikasgelan entzuten ari direnek fitxa bat daukate eskuartean eta irratsaioa amaitzear denean galderak errepikatzen zaizkie erantzuna idatz dezaten. Fitxa guztiak jaso ondoren, erantzun zuzena eman duten ikasleen artean bi izen ateratzen dira Irakasle Gelan, ausaz (neska eta mutila atera ohi dira eta irabaz- 
leak ikastalde guztietan tokatzea bilatzen da). Horrela, hurrengo irratsaioa aurreko asteko irabazleen izenak esanez hasten da beti.

Gainera, Kanpezuko irratia ez da megafonia bidez igortzen. Benetako irrati antena erosi zuten eta FM100 frekuentzian igortzen dute (ikastetxearen bueltako hedaduran soilik, oraingoz). Ikasgela bakoitzean musika-katea piztu eta irratia sintonizatuz entzuten dute saioa. Hemen ikus daiteke nola egiten duten: http://goo.gl/GyN32k.

\section{Alai Bediren sorreraren esperientzia}

2014-10-16an grabatu zen ikasturteko lehen saioa eta, ikasturtean zehar, Mikel Gartzia eta Ane Agirreren artean gidatu zen irratsaioa. Batez ere bost umerekin egin zen lan: 8 urteko bi mutil eta neska bat eta 6 urteko neska-mutil bana. Ikasturtean zehar besteren bat etorri zen probatzera eta, azken saioetan, 5 urteko beste bi mutil ere aritu ziren. Guztira 20 saio egin ziren, 30 minutukoak gutxi gorabehera.

Irratsaioa egiteaz gain eskolei parte hartzeko aukera ematea ere helburutzat genuen, baina ez zen erraza izan eskolekin lankidetzak egitea, egindako zortzi saiakeretatik bakarra burutu baitzen, Kanpezukoekin. Bertsolaritza klasea ematen zuen Oihane Perearekin ariketa bat egin zen: klase ordu bakarrean LH 5. mailako ikasleek bertsoak sortu zituzten bikoteka (bertso horiek asmakizunak ziren gainera) eta mugikor batekin grabatu ziren. Ondoren Alai Bediren saio batean beste haur batzuei jarriko genizkiela esan zitzaien. Alai Bedin bertso-asmakizunak erabili ondoren, irratsaio hori eskolara bidali zen bueltan eta horrela itxi zen zikloa: Kanpezuko haurrek beraiek sorturiko bertso-asmakizunak irratiz igorri zirela eta beste haur batzuk erantzuna asmatzen saiatu zirela ikusi zuten. Ez zen lankidetza gehiagorik egin eskolekin, irakasleekin komunikazioa eta lotura egitea zaila izan baitzen.

Bestalde, irratsaioa egiteak berez dakartzan arazoei dagokienez, umeekin aritzea ez da erraza hasieran. Arazo teknikoak daude batetik (bolumenak altuegi grabatzea, umeen entzungailuak altuegi egotea...) eta, bestetik, umeak gobernatu beharra ere izaten da (mikroen aparra uki ez dezaten, harrotuta dagoena lasaitzeko saioa gelditu behar izatea...). Gainera, umeek irratian aritzen ikasi egin behar dute pixkanaka (gauzak eskuekin keinuka ez adierazten, txandak errespetatzen, ondo ahoskatzen, irratsaioan gai aldaketa kaotikoak saihesten...).

Baina, zailtasunak zailtasun, irratia erabiliz ikas daitekeela ere ikusi genuen. Hizkuntza da, jakina, gehien lantzen den arloa (lexikoa handitzea, joskera hobetzea, mintzoa askatzea...), baina, irratian, gai eta gaitasun gehienak landu daitezke. Emaitzak (izandako arazoak eta haurren ikaskuntzak kasu) sakonago ikusi eta entzuteko, artikulu honen oinarri den Gradu Amaierako Lan osoa hemen jaits daiteke: https://goo.gl/QSqRnm. 


\section{ONDORIOAK}

\section{Irratiarekin lantzen diren gaitasunak}

Hezkuntza gaitasunen sustapenera bideratzen hasi nahi izan zenetik (Delors, 2011) denbora bat igaro da eta Euskal Autonomia Erkidegoan 8 gaitasun orokorri (Garagorri, 2007) arreta jartzen hasiak dira irakasleak. Marko teorikoan azaldu dugun bezala, haurrekin irratia egiterakoan ia nahi gabe lantzen dira gaitasun batzuk, hizkuntzari dagozkionak kasu. Eskola gehienetan irratia egitearen helburu nagusiak esparru honetakoak izan ohi dira, baina irratia ekintza komunikatiboa denez ia edozein arlo landu daiteke berarekin. Tresna hau erabiliz ez da zaila gaitasun orokorretan eragitea:

Hizkuntza-komunikaziorako gaitasuna: Gauza asko egin daitezke, irratsaioetan atal bat sor daiteke euskarazko esamoldeak proposatzen dituena, umeek aho-korapiloak ikas ditzakete... Eta ahoskera arazoak dituzten haurrentzat ere lagungarri izan daiteke irratia, beraien hizketa kanpotik entzun dezaten eta soinuen desberdintasunaz jabetu daitezen. Azken honen adibidea entzun daiteke Ttan Ttakun irratian egindako saio honetan (04:40): http://goo.gl/7pWGyg. Alai Bediren saio honetan, bestalde, pertsonaia berezi baten marrazkia deskribatu behar izan zuten, bat-batean eskatuta (19:30): goo.gl/9WuyHW.

Ikasten ikasteko gaitasuna: Ikasten jakiteko informazio iturriak ulertu egin behar dira. Irratia eginez, komunikabide izanez, ezinbestean irratia zer den ulertzen da. Horregatik, irratsaioak egiten aritu ondoren, besteek egindako irratia entzuteko jarrera kritikoagoa lor daiteke; eskola-aldizkaria egin ondoren aldizkari eta egunkari profesionalak ezberdin irakurtzen diren bezala. Gainera, irratsaioan zabalduko den informazioaren aukeraketan inplikatzen badira, irratsaioaren egitura modu sortzailean egiteko aukera badute (irakasleak bere rola aldatzeko joera baldin badu, beti gidari beharrean bidelagun izaten ere baldin badaki), ikasten ikasteko gaitasuna lantzen da.

Matematikarako gaitasuna: Matematika ere landu daiteke irratian. Denboraren jabekuntzaz eta kontrolaz gain (minutu eta segundoen zenbakiak kudeatuz), esplizituki ere landu daiteke matematika. Gaia ikasleak motibatzeko moduan proposatzea da gakoa, eta irratiak laguntzen du horretan. Radio Sol irratiko Diverclub irratsaioan matematika irakasle batek ederki egin ohi du: goo.gl/72HavL.

Informazioa tratatzeko eta teknologia digitala erabiltzeko gaitasuna: Informazioa bildu (txisteak, asmakizunak, albisteak, biografia bat, Athleticen azken partida...), landu eta gidoi batean sartu, irratsaioan irakurri (igortzen dela ohartu), ordenagailuan saioa editatu (txukundu, manipulatu...), interneten jarri edonork noiznahi entzun dezan... Horrelakoak eginez, nahiz eta gehiena irakasleak egin, ikasleek informazioaren trataeraz 
asko ikasten dute eta aukera hori eskura ikusten dute. Alai Bediko haurrak ibili ziren horrelako lanetan. Adibidez: «[Mikelek] Eta Uxune, esan, nola editatu dugu audioa? [Uxunek] Bada horrela, txuria jarri [akatsa edo ixilunea duen tartea hautatu] eta suprimir...».

Norberaren autonomiarako eta ekimenerako gaitasuna: Alai Bedi egin duten haurren artean Oladapo izan zen haurrik autonomo eta ekintzaileena. Oladapok beti eramaten zuen txiste edo ipuinen bat (ingelesez, nigeriar jatorrikoa da familia), edo «esaldi filosofiko» bat («ez egin besteei zuri egitea nahi ez duzuna»)... Batzuetan gurasoek lagunduta lortzen zituen materialak eta beste batzuetan eskolako liburutik ekartzen zituen berak, irratirako gustatu zitzaizkiolako.

Giza eta arte-kulturarako gaitasuna: Musika da irratiaren osagai nagusia, ahotsarekin batera. Irratsaioan erabiliko diren kantak haurrek aukeratzea oso motibagarria da. Musika mota ezberdinak ezagut daitezke, egileen biografiak aipatu... Bestalde, Musika irakasgaian ikasleekin zerbait grabatzea erraza da eta posta elektroniko bidez .mp3 fitxategia irrati bati eskainiz gero, seguru asko, igorriko lukete tarteren batean. Ikaskuntza komunitateez hitz egiten denean, tokiko komunikabideak ere kontuan hartu behar dira, noski.

Zientzia-, teknologia- eta osasun-kulturarako gaitasuna: Metodo eta zehaztasun zientifikoa zer diren ulertzeko ikerketen narrazioak presta daitezke (helduen mundukoak haurrentzat egokituta, edo eskolan haurrek egindako ikerketen dibulgazioa). Irratia bera baliabide teknologikoa izanik, podcast-ak blog batean jartzea, sare sozialetan partekatzea eta abar ohikoa denez, IKTen erabilera lantzea ere badakarte honelako proiektuek. Osasun-kultura ere erraz susta daiteke irratsaio batean: kargak ondo altxatzeko aholkuekin, errezeta osasungarriekin, korri egiterakoan arnasa nola hartu behar den aholkatuz...

Gizarterako eta herritartasunerako gaitasuna: Gaitasun honekin zer ulertzen den aurretik erabaki behar da (landu nahi diren balioak zein diren definitu...) eta horren araberakoa izango da gure irratsaioaren diskurtsoa; ondorioz, norabide horretan heziko dira irratsaioaren entzuleak eta baita esatariak ere (gidoiak prestatzean irakasleok asko mugatu eta bideratzen baitugu).

\section{Eskoletan irratigintza sustatzeko dauden erreparoak eta egoera hori hobetzeko proposamenak}

Ez zen erraza izan Lehen Hezkuntzako irakasleekin lankidetzak egitea. Ezin iritsi ez ibiltzeko, badaezpada ere saltsatan ez sartzea erabaki ohi dute irakasleek batzuetan, are gehiago eskolaz kanpoko eragileekin. 
Hona hemen lau ildo, eskolek irratia gehiago erabil dezaten:

- Irakasleak lehen aldiz irratia egiten edo bestelako berrikuntzatan sartzeko, oinarrizkoa da lan baldintza duinak izatea. Ezin iritsi dabilenak ez du lan gehiago hartuko, noski.

- Lehenbiziko aldian irratiko norbait ikasgelaraino joan dadila, erraza dela ikusteko. Ondoren, Audacity software askeko audio editorea instalatu eta erabiltzen irakats diezaiela (30 minutuko gauza da). Eta, azkenik, beren kabuz hasteko gogoa duten irakasleei lehen irratsaioekin lagundu diezaiela, betiere gero bakarrik jarraituko dutela abisatuz.

- Eskola-irrati asko existitzen da jadanik. Ohituraz, ikastetxeek beren webgunean jarri ohi dituzte edukiak eta horiei hedapena eman behar liekete irrati libre, publiko eta komertzialek. Irratiek internet bidez umeen podcast-ak eskuratu eta beren programazioaren baitan igorri behar lituzkete (horrek, automatikoki, lanean ari diren eskola-irratiengan eragin bizigarri itzela ekarriko luke).

- Aipaturiko Txanelaren liburuki horretan (Ikastolen Elkartea, 2003) programatutakoak asko erraztu die irakasle batzuei (Salburua eta Ramon Bajokoei kasu) irratsaio baten Proiektua egitera animatzea: oraindik urte luzez existituko diren eskoletarako liburuek, testuliburuek, horrelako proiektu ireki gehiago sustatu beharko lukete.

\section{Irratia egiteko moduak}

Egiteko bideak askotarikoak izanik, eskolak irratia erabiltzea erraza dela ikusi dugu eta ikastetxe ugarik erabiltzen dutela jaso dugu. Hezkuntza Sailak hizkuntza normalkuntzarako NOLEGA programaren baitan irratia erabiltzeagatik diru-laguntza ematen die eskolei eta, zerrenda zehatzik lortu ez genuen arren, aurreko urteetan EAEn diru-laguntza hori 150 ikastetxe inguruk eskatu izan dutela esan ziguten Hezkuntza Sailetik. Kanpezuko Mendialdea IPIk jasotzen du laguntza hori, adibidez.

Bestalde, Euskal Herrian behintzat, gaur egun, komunikabideak eskolara gerturatzeko prest badaudela ikusi da eta, nahiz eta irakasleei eskolatik ateratzea kostatzen zaien, egiten dira gauza politak.

Gaur egun eskolek irratia baliabide pedagogiko gisa erabiltzeko aukera bermatuta daukatela uste dugu.

Laburtzeko, eskolak irratia egiteko lau era dituela esan daiteke, aukera hauek guztiak elkarren artean konbinagarri direlarik:

- Simulazioa egiteko izara bat baino ez da behar.

- Megafonia, eskola barruan aritzeko (zuzenean ala aurretik grabatuta). 
- FM bidez igortzea, irrati profesional batekin edo eskolak berak (Kanpezun bezala).

- Internetez, eskolaren web orrian edo blogean audio fitxategiak jarriz.

Beraz, gure esperientziaren berri emanez, eskolak animatu nahi ditugu irratia proba dezaten.

\begin{abstract}
This article has analyzed the benefit of radio as a teaching resource and the current use in six schools in Alava, from kindergarten to Primary. There are also described four other cases in Euskal Herria, where professional radios offer their services to schools. Finally, it explains how during the academic year 2014-2015, a new children's radio program was made in the Hala Bedi Radio of VitoriaGasteiz, an experience that helped to experiment and see the educational possibilities of this medium.
\end{abstract}

Keywords: Citizenship education, Primary education, Radio, Educational radio, Digital divide, ICT.

En este artículo se ha analizado la utilidad de la radio como recurso didáctico y el uso que actualmente se le da en 6 centros educativos de Álava, tanto en Educación Infantil como, en mayor medida, en Primaria. También se describen en otros territorios de Euskal Herria 4 casos en los que radios profesionales ofrecen sus servicios a las escuelas. Por último, se explica cómo durante el curso académico 2014-2015 se creó un nuevo programa infantil en la radio Hala Bedi de Vitoria-Gasteiz que permitió experimentar las posibilidades educativas de este medio de comunicación.

Palabras clave: Educación para la ciudadanía, Educación Primaria, Radio, Radio escolar, Brecha digital, TIC.

Cet article analyse l'utilité de la radio comme ressource didactique et son utilisation actuelle dans 6 centres éducatifs d'Araba, au Niveau Maternelle et dans une plus grande mesure, au Niveau Elémentaire. Egalement, 4 cas d'autres territoires d'Euskal Herria sont 
décrits, dans lesquels les professionnels de la radio offrent des services aux écoles. Enfin, l'article explique comment un programme de radio à destination des enfants a été créé à la radio Hala Bedi de Vitoria-Gasteiz durant l'année académique 2014-2015, une expérience qui a permis d'expérimenter et d'évaluer les possibilités éducatives de ce média.

Mots-clé: éducation citoyenne, niveau élémentaire, radio, radio éducative, fracture numérique, TIC.

\section{ERREFERENTZIAK}

Ambròs, A. eta Breu, R. (2011). 10 ideas clave. Educar en medios de comunicación. La educación mediática. Bartzelona: GRAÓ.

Aparici, R. (1993). La revolución de los medios audiovisuales: educación y nuevas tecnologías. Madril: Ediciones de la Torre.

Areizaga, R. (2012). Atsotitzak edo esaera-zaharrak. [Blog mezua] Hemendik berreskuratua: goo.gl/vc3Kwf

Arnal, A. et al. (1998). Arabako gida. Haurrek idatzia. Vitoria-Gasteiz: Gráficas Vilar (A Punto Elkarteak egina Caja Vital Kutxa Fundazioaren laguntzarekin).

Delors, J. (2011). La educación esconde un tesoro. (Correo de la UNESCO) [PDF dokumentua]. Hemendik berreskuratua: goo.gl/8klZ8Z

Eizagirre, P. (2015). Aittu! (ipuin irakurriak) [Web orria]. Hemendik berreskuratua: http://aittu.net/

Euskara Kultur Elkargoa (2010). Mikroipuinak 2008 eta 2009 [PDF dokumentua]. Iruñea: Pamiela. Hemendik berreskuratua: goo.gl/3O95Aq

Eusko Jaurlaritza (2007). 175/2007 Dekretua. IV. eranskina: Lehen Hezkuntzako atalak. Arloa: Hizkuntzak. Hemendik berreskuratua: http://goo.gl/qEu2lB

Eusko Jaurlaritza (2009). Oinarrizko gaitasunak lehen hezkuntzan. Vitoria-Gasteiz: Eusko Jaurlaritza. Hemendik berreskuratua: http://goo.gl/jlLyJm

Frantziako Gobernua (2002). Bulletin Officiel du Ministère de l'Éducation Nationale et du Ministère de la Recherche (N. 114 févr. 2002). Hemendik berreskuratua: http://goo.gl/6BLwi4

Garagorri, X. (2007). Konpetentzietan oinarritutako curriculumaren diseinua eta garapena bideratzeko lorratzak [PPT aurkezpena]. Bilbao. Hemendik berreskuratua: goo.gl/Zc5t1r

Gartzia, M. (2015). Eskola eta Irratia (Gradu Amaierako Lana). EHU, VitoriaGasteiz. Hemendik berreskuraua: https://goo.gl/QSqRnm

Gutierrez, A. eta Fernandez, I. (2005). Irratsaio bat egiteko tailer praktikoa [PDF dokumentua]. Bilbao: UEU. Hemendik berreskuratua: http://goo.gl/R8PBvr

Ikastolen Elkartea. (2003). Gora Gutenberg! Gora Marconi! (LH 2, 6. liburukia) Txanela Proiektua. Andoain: Elkar.

Illich, I. (1971). La sociedad desescolarizada [PDF dokumentua]. Mexiko: 1985eko edizioa. Hemendik berreskuratua: goo.gl/cNDFc6 
Mallas, S. (1979). Medios audiovisuales y pedagogía activa. Bartzelona: CEAC S.A.

Millares et al. (2003). Medios de comunicación y educación. Bartzelona: CISSPRAXIS, S.A.

Nafarroako Foru Aldundia (2014). Nafarroako foru komunitateko lehen hezkuntzako curriculuma (174. NAO). Iruñea. Hemendik berreskuratua: http://goo. $\mathrm{gl} / \mathrm{Q} 2 \mathrm{hkLj}$

Ortego, A. (2014). Eskola irrati komunitarioak sarean: Ahozko komunikazioaren garapena podcasten bidez (Gradu Amaierako Lana). EHU, Donostia.

Porcher, L. (1980). Medios audiovisuales. Aplicación a la Lengua, Matemáticas, Ciencias Naturales y Sociales, Idiomas, Plástica y Tecnología. Madril: Editorial Cincel.

Ruiz Bikandi, U. et al. (2009). Bigarren hizkuntzaren didaktika Haur eta Lehen Hezkuntzan. (2. arg.). Bilbao: EHU.

Sevillano, M.L. et al. (1998). Nuevas tecnologías, medios de comunicación y educación. Formación inicial y permanente del profesorado. Madril: Editorial CCS.

Ugalde, J. J. (2008). Irratia eskolan: oinarrizko orientabideak. (2008). Gasteiz: Eusko Jaurlaritza.

UNESCO (1950). Radio in fundamental education. Paris: UNESCO.

UNESCO (1982). Grunwald Declaration on Media Education [PDF dokumentua]. Hemendik berreskuratua: goo.gl/m9eGUg

Woods, P. (1987). La escuela por dentro. La etnografía en la investigación educativa. Bartzelona: Paidós.

\section{Artikuluan zehar aipaturiko irratsaioak eskuratzeko estekak}

Ttan Ttakun irratia. Aitor Ikastolaren Irratsaioak [Podcastak]: http://goo. $\mathrm{gl} / 7 \mathrm{pWGyg}$

Hondarribiko Talaia Eskola. Irratsaioak [Podcastak]: goo.gl/rkTZY1

Bizkaia Irratia. Zortziko Txikia [Podcastak]: http://goo.gl/3jGsqH

Bilbo Hiria Irratia. Gaur Ez Dago Eskolarik [Podcastak]: goo.gl/LTJ3Fh

Umandi Ikastola. Bil bil bil Irratia [Podcastak]: goo.gl/QrfDat

Odon de Apraiz Ikastola. Txutxu-mutxu Irratia [Podcastak]: goo.gl/D4aENM

Mendialdea IPI (2014-12-05). 3. IRRATSAIOA: HH 5 URTEKOEN ETA LH 4. MAILAKOEN IRRATSAIOA [Blog posta]: http://goo.gl/GyN32k

Radio Sol. Diverclub [Podcastak]: goo.gl/72HavL

Mikelsgartzia (2015-4-17). 2014-11-6 EkiNaia [Alai Bediren Podcast bat]: goo. gl/9WuyHW 